\title{
Prevalence of healthcare-associated infection at a tertiary hospital in the Northern Cape Province, South Africa
}

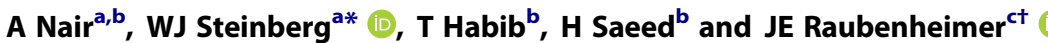 \\ ${ }^{a}$ Department of Family Medicine, University of the Free State, Bloemfontein, South Africa \\ ${ }^{b}$ Department of Family Medicine, Kimberley Hospital Complex, Kimberley, South Africa \\ ${ }^{c}$ Department of Biostatistics, University of the Free State, Bloemfontein, South Africa \\ *Corresponding author, email: SteinbergWJ@ufs.ac.za
}

Background: Healthcare-associated infections (HCAls) are a well-known public health threat; however, published data on the endemic burden of HCAls in sub-Saharan Africa are limited. This study aimed to determine the prevalence of primary bloodstream infection (PBSI), surgical site infection (SSI), lower respiratory tract infection (LRTI) and urinary tract infection (UTI) at Kimberley Hospital Complex (KHC), Northern Cape.

Methods: A one-day pointprevalence survey was conducted between February 2016 and March 2016 on all patients admitted to 15 selected wards at KHC. The Standardised Centers for Disease Control and National Nosocomial Infection Surveillance Systems criteria were used.

Results: A total of 326 patients were surveyed and the overall HCAI prevalence rate was $7.67 \%$. This included $4.60 \%$ SSIs, $1.53 \%$ UTIs, $0.92 \%$ PBSIs and $0.92 \%$ LRTIs. Patients with HCAI stayed a mean of 20.8 days compared with 9.1 days for the remaining patients. Almost $75 \%(n=240)$ of the surveyed patients had one or more recognised risk factors. The most isolated microorganism among the 11 microorganisms isolated was Klebsiella pneumoniae (36.4\%). Half (54.5\%) of the isolated organisms were resistant to penicillin. At the time of the survey, $42.0 \%$ of all the patients were on antimicrobials of which amoxicillin/clavulanic acid was most commonly prescribed (29.9\%).

Conclusion: The overall HCAI prevalence rate found in KHC is encouraging, but the prevalence of SSI is of concern. Further studies are needed to identify risk factors and target this as an area where preventative interventions can be implemented.

Keywords: healthcare-associated infections, infection control, Kimberley, pointprevalence, risk

\section{Introduction}

Healthcare-associated infections (HCAls) originate in patients while admitted to hospital, denoting a new disorder that was not present/incubating at the time of admission or the residual of an infection acquired during a previous admission. ${ }^{1}$ The terms 'hospital-acquired' and 'nosocomial' are often used interchangeably, but in essence refer to infections that present for the first time in hospitalised patients at least 48 hours after admission. ${ }^{2}$

Healthcare-associated infections have numerous repercussions such as an increase in disability and morbidity, and eventually have the potential to result in death. Patients who develop nosocomial infections increase healthcare costs by longer length of stay and, as a result, the need for more diagnostic tests and treatment. ${ }^{3} \mathrm{~A}$ World Health Organization (WHO) study showed that the overall increase in the length of stay for patients with surgical wound infections was 8.2 days, ranging from 3 days for gynaecology to 9.9 days for general surgery and 19.8 days for orthopaedic surgery. ${ }^{3}$ There are also indirect costs to the patient secondary to possible loss of income and inability to provide for the needs of the family. Legal costs cannot be ignored in the present environment of litigation, especially when nosocomial infections are often attributed to negligence or substandard health care. ${ }^{4}$
Many patient factors influence the acquisition of nosocomial infections, such as age, immune status, pre-existing disease and diagnostic or therapeutic interventions. Paediatric and geriatric patients are especially prone to infection. ${ }^{3}$ Patients with chronic diseases, such as malignant tumours, diabetes mellitus, renal failure or AIDS are vulnerable to infections, especially to opportunistic organisms. ${ }^{3}$ Modern diagnostic and therapeutic procedures (biopsies, endoscopic examinations, catheterisation, intubation/ventilation and surgical procedures) also increase the risk of contracting HCAls. Other contributing risk factors are crowded conditions within the hospital, frequent transfers of patients from one unit to another, and concentration of patients highly susceptible to infection, such as neonates, burn patients and patients in intensive care units (ICU), in one area. ${ }^{4}$ Infections caused by antimicrobial-resistant pathogens are a major concern and HCAls are therefore becoming more difficult and costly to manage and treat. Yet, it has been noted that $15-$ $30 \%$ of HCAls may be avoidable. ${ }^{5}$

Surveillance refers to the systematic, ongoing observation of the occurrence and distribution of disease in a population and the events or conditions that increase or decrease the risk of disease. ${ }^{6}$ The gold standard for HCAl surveillance would be prospective, on-site, continuous, hospital-wide surveillance, but this kind of approach requires numerous resources. Point prevalence surveys are the most common type of surveillance done because

${ }^{\dagger}$ [Current affiliation] Senior Research Fellow, Sydney Medical School, Discipline of Pharmacology, The University of Sydney, Translational Australian Clinical Toxicology Programme, Australia 
they are less demanding when it comes to human and technical resources. ${ }^{7}$

A meta-analysis done in 2011 found that $66 \%$ of developing countries worldwide had no published data on the endemic burden of HCAI. Yet the available evidence is sufficient to raise concerns that nosocomial infections are significantly adding to the already high burden of infection in sub-Saharan Africa. ${ }^{2}$ The true burden of HCAls in South Africa is poorly studied. It is assumed to be higher in the public sector compared with the private sector. This uncertainty does not assist in directing the scarce resources at our disposal effectively. More detailed analyses and reporting of HCAl rates are needed to identify areas where one can make an impact. ${ }^{8}$

A prevalence survey, similar in methodology and definitions to our study, was done in South Africa in 2005 involving four public and two private healthcare facilities. The combined prevalence was $9.7 \%$ with the highest rates found in the paediatric wards. Urinary tract infections and pneumonias were the predominating HCAls. This was attributed to the fact that more than half of the public hospital admissions were HIV-related. ${ }^{9}$ The extent of the problem of HCAl is poorly defined in the South African context, as outbreak responses are generally reactive, not proactive.

\section{Aim and objectives}

The aim of this study was to determine the point prevalence of HCAl at a tertiary hospital in Kimberley, Northern Cape.

Objectives included identifying risk factors in patients susceptible to primary bloodstream infection (PBSI), surgical site infection (SSI), lower respiratory tract infection (LRTI) and urinary tract infection (UTI) in healthcare units.

\section{Method}

\section{Study design and setting}

This is a point prevalence survey conducted at the Kimberley Hospital Complex (KHC) in the Northern Cape. The aim was to complete at least one ward per day during the study period from February 2016 to March 2016.

Kimberley Hospital Complex is a provincial tertiary hospital with 604 beds serving roughly 97000 patients annually. It serves the people of Kimberley on a primary, secondary and tertiary platform as well as being a referral centre for the entire Northern Cape Province. The catchment areas include distant towns such as Springbok (775 km away), Calvinia (648 km away), Upington (410 km away), as well as closer towns such as Hartswater (117 km away) and Barkley West (35 km away).

\section{Study population}

The study population consisted of all inpatients who were present in the selected ward(s) on the day of the survey. The sample population thus included all patients occupying a bed in five general surgery wards ( $n=134$ beds), three internal medicine wards ( $n=125$ beds), three paediatric wards ( $n=111$ beds), two orthopaedic wards ( $n=61$ beds), one obstetrics and gynaecology ward ( $n=33$ beds) and one ophthalmology ward ( $n=24$ beds). The inclusion criteria were all eligible patients present in the selected ward on the day of the survey, provided they were willing and had given informed consent. Patients in outpatient areas, emergency departments, burns unit, psychiatry, ICUs, short-stay wards and rehabilitation units were excluded.

\section{Measurement tool}

A standardised and validated data collection form ${ }^{9}$ was adapted from the United Kingdom (UK) and pioneered locally by the Michael Emmerson/South African HCAl surveillance centre (SAHISC) at the University of the Witwatersrand. The researchers used an international coding system developed by the Centers for Disease Control (CDC) and National Nosocomial Infection Surveillance Systems (NNIS) that included codes for ward type, main diagnoses, antimicrobials and microorganism list. ${ }^{10}$

The data collection form consisted of four sections: survey details, patient details, HCAl-related risk factors and details of the HCAl, if identified. Information was entered by using numbers, letters or crosses. Data collected for each patient included: age, sex, date of patient admission, main diagnosis, specialty area of the patient's care, presence of invasive devices on the day of the survey, and risk factors, such as diabetes and immunodeficiency. Standardised Centers for Disease Control and Prevention National Nosocomial Infection Surveillance Systems criteria ${ }^{10}$ were then used to determine if the patient had one or more active HCAls present and/or received antimicrobial treatment for it. For patients identified with $\mathrm{HCAl}$, the site of infection, date of onset and specific pathogens were recorded.

\section{Data collection}

Data were gathered from nursing notes, medical notes, temperature charts, drug charts, radiology reports, surgical notes, laboratory reports and other relevant charts, such as care plans.

The data collection was done by two of the authors, one of whom was the main researcher, with the assistance of two infection control sisters working at the hospital. The main researcher trained the other members regarding the various aspects of the data collection by means of group discussions as well as practical illustrations in the completion of the data collection form.

\section{Pilot study}

A total of 26 patients in one of the surgical wards at KHC were surveyed on June 4,2015 . The aim was to validate the measurement tool by comparing the data collection forms completed by two independent data collectors surveying the same patients at the same time. Inter-investigator variability in the collection of data was assessed.

\section{Statistical analysis}

The data were analysed by the Department of Biostatistics, Faculty of Health Sciences, University of the Free State (UFS), using SAS/STAT ${ }^{\oplus}$ software, version 9.4 of the SAS System for Windows (SAS Institute, Cary, NC, USA). The point prevalence of HCAI was reported as the percentage of patients with at least one active HCAl out of the total number of patients. The prevalence of antimicrobial use was reported as the percentage of patients receiving at least one antimicrobial agent out of the total number of patients. Odds ratios (ORs) with $95 \%$ confidence intervals $(\mathrm{Cl})$ were calculated where relevant.

\section{Ethical consideration}

The protocol was approved by the Ethics Committee of the Faculty of Health Sciences, UFS (ECUFS NR 175/2014) and the Provincial Health Research and Ethics Committee from the Northern Cape Department of Health (NC_2015RP26_707). Permission to conduct the study was granted by the Head of Clinical Management at KHC. 
Table 1: Point prevalence of healthcare-associated infections according to patient characteristics

\begin{tabular}{|c|c|c|c|c|}
\hline Factor & All patients $(n)$ & Patients with HCAI (n) & Prevalence of HCAI (\%) & OR $(95 \% \mathrm{Cl})$ \\
\hline & 326 & 25 & 7.67 & - \\
\hline \multicolumn{5}{|l|}{ Sex: } \\
\hline Male & 152 & 12 & 7.89 & $1.06(0.46-2.40)$ \\
\hline Female & 174 & 13 & 7.47 & 1 \\
\hline \multicolumn{5}{|l|}{ Age groups (years): } \\
\hline $0-5$ & 88 & 5 & 5.68 & $1.39(0.15-12.46)$ \\
\hline $6-15$ & 15 & 1 & 6.67 & $1.64(0.10-28.41)$ \\
\hline $16-30$ & 50 & 4 & 8.00 & $2.00(0.21-18.93)$ \\
\hline $31-50$ & 70 & 9 & 12.86 & $3.39(0.41-28.30)$ \\
\hline $51-70$ & 78 & 5 & 6.41 & $1.58(0.18-14.18)$ \\
\hline$>70$ & 24 & 1 & 4.17 & 1 \\
\hline \multicolumn{5}{|l|}{ Per ward: } \\
\hline General surgery & 78 & 6 & 7.69 & 1 \\
\hline Internal medicine & 73 & 3 & 4.11 & $0.51(0.12-2.14)$ \\
\hline Paediatrics & 98 & 6 & 6.12 & $0.78(0.24-2.53)$ \\
\hline Orthopaedics & 45 & 7 & 15.56 & $2.21(0.69-7.05)$ \\
\hline Obstetrics and gynaecology & 27 & 3 & 11.11 & $1.5(0.35-6.47)$ \\
\hline Ophthalmology & 5 & 0 & 0 & 0 \\
\hline
\end{tabular}

Cl: confidence interval; HCAl: healthcare-associated infection; OR: odds ratio.

Patients received an information leaflet to explain the study. Verbal and written informed consent was obtained after explanation of the study in person. For participants younger than seven years, parents gave consent on behalf of the child. For participating children between the ages of 7 and 18 years, parents gave consent while the children gave assent. There were no interventions or interference with the management of patients in the ward. All the information was managed confidentially and stored securely to minimise access. Databases were password-protected and the completed questionnaire forms as well as the consent forms were kept under lock and key.

\section{Results}

The study included 326 patients. The overall bed occupancy of the wards at the time of survey was $66.8 \%$ (326/488). The highest bed occupancy was in paediatrics at $88.3 \%(98 / 111)$ and the lowest occupancy in ophthalmology at $20.8 \%(5 / 24)$.

As shown in Table 1, just over half of the patients were female $(53.4 \%, n=174)$. The median age of all the patients surveyed was 46 years (range: 28 days to 91 years). The highest percentage of patients was in the age group $0-5$ years $(27.0 \%)$ followed by $23.9 \%$ in the age group $51-70$ years.

The overall point prevalence of HCAI was $7.67 \%(n=25)$. There was a slightly higher prevalence of HCAl among male patients (7.89\%) compared with female patients $(7.47 \%)$. Age was treated as a categorical variable and distributed into the following age groups: $0-5$ years, $6-15$ years, $16-30$ years, $31-50$ years, $51-70$ years, and $>70$ years. The highest prevalence of HCAl was in the age group $31-50$ years $(12.86 \%)$ and the lowest in the age group > 70 years $(4.17 \%)$. The orthopaedic wards had the highest prevalence $(15.56 \%)$ of patients with HCAI and the lowest was in ophthalmology where none of the five patients had an HCAl. As shown in Figure 1, the mean length of stay for the infected patients was 20.8 days ( $95 \% \mathrm{Cl} 12.1$ to 29.4), while the mean length of stay for the remaining patients was lower at 9.1 days $(95 \% \mathrm{Cl} 7.8$ to 10.5$)$.
Of the 25 patients with HCAl, only one patient, admitted to a general surgery ward, had two HCAls (SSI and UTI) resulting in a total HCAl burden of $n=26$. Table 2 shows that almost $60 \%$ of HCAls were SSIs, mostly superficial incisional. The prevalence of SSI in all the patients surveyed was $4.60 \%$. Primary BSI and LRTI had the lowest prevalence of $0.92 \%$ each.

The three cases of LRTI were diagnosed on clinical grounds and $X$-ray changes with no microbiological confirmations. Three of the five UTIs were microbiologically confirmed and identified as Candida albicans, Klebsiella pneumoniae and Enterobacter cloacae.

\section{Risk factors}

Almost three-quarters $(73.6 \%, n=240)$ of the 326 surveyed patients had one or more of the 12 listed risk factors. Half $(50.9 \%)$ of all the patients had a peripheral vascular catheter inserted, $10.4 \%$ a urinary catheter and $1.5 \%$ a central

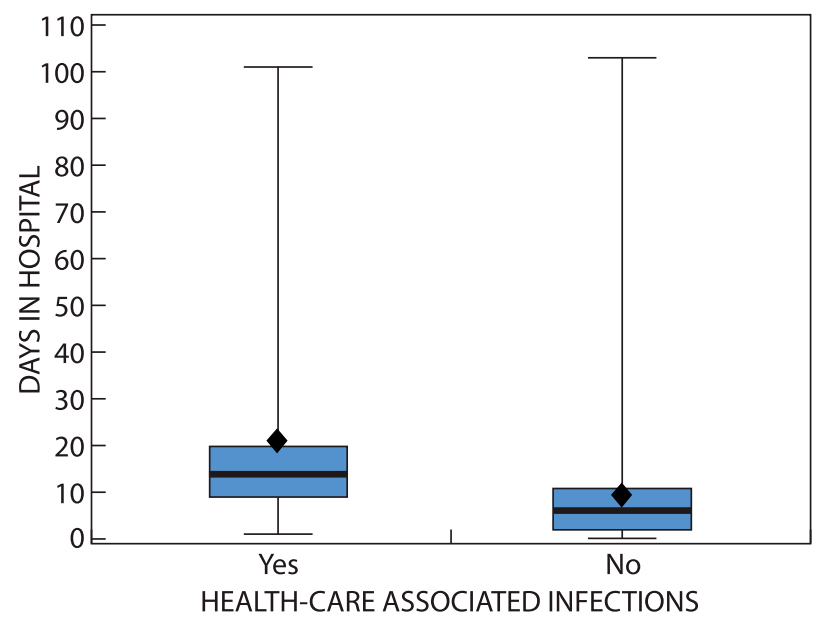

Figure 1: Boxplot of days in hospital for patients with and without healthcare-associated infections. 
Table 2: Prevalence rates according to the type of healthcare-associated infections $(n=26)$

\begin{tabular}{|c|c|c|c|c|}
\hline Type of HCAI & Types of organisms isolated & $\begin{array}{c}\text { Number of } \\
\text { occurrences }(n)\end{array}$ & $\begin{array}{l}\text { Percentage of total } \\
\text { number of HCAls (\%) } \\
n=26\end{array}$ & $\begin{array}{l}\text { Prevalence of HCAI by infection } \\
\text { type among patients surveyed } \\
\text { (\%) } n=326\end{array}$ \\
\hline $\begin{array}{l}\text { Primary } \\
\text { bloodstream } \\
\text { infection }\end{array}$ & Klebsiella pneumoniae & 3 & 11.5 & 0.92 \\
\hline $\begin{array}{l}\text { Surgical site } \\
\text { infection }\end{array}$ & & 15 & 57.7 & 4.60 \\
\hline Deep incisional & $\begin{array}{l}\text { Acinetobacter baumannii; } \\
\text { Staphylococcus aureus }\end{array}$ & 4 & 15.4 & 1.23 \\
\hline Organ/space & nil cultured & 1 & 3.8 & 0.31 \\
\hline $\begin{array}{l}\text { Lower respiratory } \\
\text { tract infection }\end{array}$ & nil cultured & 3 & 11.5 & 0.92 \\
\hline
\end{tabular}

HCAl: healthcare-associated infection.

intravascular catheter. A quarter (26.1\%) of the patients had undergone surgery and $22.7 \%$ were immunodeficient.

None of the following risk factors was noted in patients diagnosed with HCAl: parenteral nutrition, chemotherapy, central intravascular catheter, or mechanical ventilation. For the 25 patients with HCAl: $64.0 \%(n=16)$ had a peripheral vascular catheter inserted, $56.0 \%(n=14)$ were post-surgery, $24.0 \%$ $(n=6)$ had an immunodeficiency and $20.0 \%(n=5)$ had a urinary catheter in situ. Three patients (12.0\%) had diabetes and one patient (4.0\%) was diagnosed with neutropenia. One patient $(4.0 \%)$ received a blood transfusion and one patient $(4.0 \%)$ was on steroids.

Table 3 shows the prevalence of HCAl among all the surveyed patients with and without the listed risk factors. The only statistically significant difference between the two groups was for surgery $(p$-value $<0.001)$ with increased odds of 4.12 .

As can be seen in Table 3, certain risk factors were associated with higher prevalence of HCAl such as surgery at $16.47 \%$ and urinary catheter at $14.71 \%$. In comparison, patients with immunodeficiency (includes patients with AIDS, HIV with CD4 <500, leukaemia and lymphomas) had a prevalence of $8.11 \%$. Patients had between one and five risk factors, with a median of two risk factors.

\section{Antimicrobial treatment}

Overall, 137 (42.0\%) patients were treated with at least one antimicrobial agent. Amoxicillin/clavulanic acid was the prominent drug of choice and this was uniform among the various disciplines.

Of the 25 patients with $\mathrm{HCAl}$, nine (36.0\%) were prescribed amoxicillin and an enzyme inhibitor - co-amoxiclav. Three patients (12.0\%) were not on antimicrobial therapy. Antimicrobial therapy for the remaining patients with HCAl included ampicillin $(n=3)$, ciprofloxacin $(n=3)$, sulfamethoxazole and trimethoprim (co-trimoxazole), fluconazole, gentamicin/ampicillin, ceftriaxone, amoxicillin, azithromycin, and gentamicin $(n=1$ each).

Eleven organisms were isolated among the patients with HCAl who had specimens sent for microbiological evaluation. This included four cases of Klebsiella pneumoniae, two cases of Pseudomonas aeruginosa, two cases of Staphylococcus aureus and one case each of Candida albicans, Acinetobacter baumannii and Enterobacter cloacae. Half $(54.5 \%, n=6)$ of the isolated

Table 3: Risk factors for healthcare-associated infections $(n=326)$

\begin{tabular}{|c|c|c|c|c|c|c|c|}
\hline \multirow[b]{3}{*}{ Risk factor } & \multicolumn{6}{|c|}{ Prevalence of HCAl in patients with and without risk factors } & \multirow[b]{3}{*}{ OR (95\% Cl) } \\
\hline & \multicolumn{3}{|c|}{ With risk factor } & \multicolumn{3}{|c|}{ Without risk factor } & \\
\hline & $\begin{array}{c}\text { All } \\
\text { patients } \\
(n)\end{array}$ & $\begin{array}{l}\text { Patients with } \\
\text { HCAI (n) }\end{array}$ & $\begin{array}{c}\text { Prevalence } \\
\text { (\%) }\end{array}$ & $\begin{array}{c}\text { All } \\
\text { patients } \\
\text { (n) }\end{array}$ & $\begin{array}{l}\text { Patients with } \\
\text { HCAI (n) }\end{array}$ & $\begin{array}{c}\text { Prevalence } \\
\text { (\%) }\end{array}$ & \\
\hline $\begin{array}{l}\text { Peripheral vascular } \\
\text { catheter }\end{array}$ & 166 & 16 & 9.64 & 160 & 9 & 5.63 & $1.79(0.76-4.18)$ \\
\hline Surgery & 85 & 14 & 16.47 & 241 & 11 & 4.56 & $4.12(1.79-9.49)$ \\
\hline Immunodeficiency & 74 & 6 & 8.11 & 252 & 19 & 7.54 & $1.08(0.42-2.82)$ \\
\hline Diabetes & 46 & 3 & 6.52 & 280 & 22 & 7.86 & $0.82(0.24-2.85)$ \\
\hline Urinary catheter & 34 & 5 & 14.71 & 292 & 20 & 6.85 & $2.35(0.82-6.72)$ \\
\hline Steroids & 31 & 1 & 3.23 & 295 & 24 & 8.14 & $0.38(0.05-2.88)$ \\
\hline Blood transfusion & 25 & 1 & 4.00 & 301 & 24 & 7.97 & $0.48(0.06-3.71)$ \\
\hline Neutropenia & 11 & 1 & 9.09 & 315 & 24 & 7.62 & $1.21(0.15-9.88)$ \\
\hline
\end{tabular}

$\mathrm{Cl}$ : confidence interval; HCAl: healthcare-associated infection; OR: odds ratio. 
organisms were resistant to penicillin, $36.4 \%(n=4)$ were resistant to cephalosporin and $27.3 \%(n=3)$ were resistant to aminoglycosides.

\section{Discussion}

This was the first point prevalence survey of HCAl conducted at KHC. The overall prevalence rate was found to be $7.67 \%$. Among the individual infection types investigated, the highest prevalence was for SSI (4.60\%) followed by UTI (1.53\%) with PBSI and LRTI both at $0.92 \%$. Superficial incisional subtype made up almost $67 \%$ of the SSIs.

Healthcare-associated infections (HCAl) were found to result in significantly longer lengths of stay. The direct and indirect costs of increased lengths of stay due to HCAls are well described, ${ }^{4}$ and the $\mathrm{WHO}^{3}$ notes that not only are 'the economic costs [are] considerable ... [but] the increased length of stay for infected patients is the greatest contributor to cost' (emphasis added). In a country such as South Africa with an overburdened healthcare system, these costs seem too expensive to afford.

The UK has been a forerunner in conducting HCAI prevalence surveys, already completing three massive surveys involving multiple countries. ${ }^{11-13}$ The HCAl prevalence rate varies among countries with Germany having a low rate of $3.5 \%$ while countries with lower socioeconomic backgrounds, such as Tunisia, have rates as high as $17.9 \% .^{14,15}$

An HCAl prevalence survey, using methodology similar to our study, was conducted in 2008 at 39 hospitals in different provinces in Argentina. ${ }^{6}$ The authors of the Argentinian study also compared their results with results from England, Wales, Ireland and South Africa. ${ }^{9,16}$ As shown in Table 4, the overall $\mathrm{HCAl}$ point prevalence rate at KHC was lower than the rates reported for Argentina and Gauteng, South Africa, but comparable to the England and Wales rates. One must keep in mind that ours was a single hospital survey while other surveys included many hospitals. Therefore, in a South African context, if many hospitals were involved with variable prevalence rates, the overall rate in South Africa may be higher than that at KHC. However, in South Africa, the national prevalence survey is still insufficiently representative for comparison.

Similarly, results from the surveys done in England, Wales and Ireland, ${ }^{16}$ Argentina, ${ }^{6}$ as well as studies done in $\operatorname{Iran}^{7}$ and in the United States ${ }^{17}$ showed that SSI seemed to be the most prominent $\mathrm{HCAl}$, even though the overall prevalence rates varied between the different countries. In comparison, PBSIs were found to be more prevalent in the Gauteng study in South Africa compared with the other HCAls. ${ }^{9}$ This can be explained by the fact that the hospitals involved in the Gauteng study included two academic hospitals and two large private hospitals. The use of central intravascular catheters and other invasive procedures was more common and may have contributed to the high rate of $\mathrm{PBSI}{ }^{9}$

The high odds ratio of 4.12 of surgery as a risk factor for HCAI confirms the link between the surgery performed at KHC and the development of HCAl. The strong link between surgery and SSI is apparent. This calls for prevention of SSI by adherence to sterile techniques while busy with surgical procedures at KHC.

Overall, 137 (42.0\%) patients were treated with at least one antimicrobial agent. The most prominent resistance profile was to penicillin (54.5\% of the 11 isolated organisms). Amoxicillin/clavulanic acid was the prominent drug of choice and this was uniform among the various disciplines. A possible explanation of high resistance to penicillin may be due to the prominent use of amoxicillin/clavulanic acid across all disciplines.

The most prevalent microorganism was Klebsiella pneumoniae (36.4\% of the 11 isolates in patients with HCAl). This is of concern, as the principal pathogenic reservoirs for transmission of Klebsiella are the gastrointestinal tract and the hands of hospital personnel. The ability of this organism to spread rapidly often leads to nosocomial outbreaks, especially in neonatal units. Strict adherence to basic epidemiological standards for the management of urinary catheters, intravenous drips, tracheostomies, wounds, maintenance and care of equipment, and good hand hygiene practices aid in preventing the spread of nosocomial Klebsiella infections. ${ }^{18}$

\section{Strengths and limitation of study}

Standardised tools and methodology were used to conduct this study, making it comparable to other national and international studies. However, being a point prevalence survey at a single hospital site, there is a short period of observation leading to possible bias towards identifying $\mathrm{HCAl}$ and antimicrobial use for those infections with a longer duration of illness and longer inpatient stays as well as the inability to capture outbreaks of HCAl occurring between surveillance time-points.

The confidence intervals for the sub-strata were wide and in many cases overlapping, suggesting large variability in HCAl data. This is due to the small sample size in this study compared with national studies that had higher numbers of patients, and

Table 4: Comparative healthcare-associated infection rates for Kimberley Hospital Complex and South Africa, Argentina, Ireland, Wales and England

\begin{tabular}{|c|c|c|c|c|c|}
\hline \multirow[b]{2}{*}{ Location } & \multicolumn{5}{|c|}{ HCAI prevalence (\%) } \\
\hline & Overall & $\begin{array}{c}\text { Primary bloodstream } \\
\text { infection }\end{array}$ & $\begin{array}{l}\text { Lower respiratory tract } \\
\text { infection }\end{array}$ & $\begin{array}{l}\text { Surgical site infection } \\
\text { (surgical patients only) }\end{array}$ & $\begin{array}{l}\text { Urinary tract } \\
\text { infection }\end{array}$ \\
\hline $\begin{array}{l}\text { Kimberley Hospital } \\
\text { Complex }\end{array}$ & 7.67 & 0.92 & 0.92 & 4.60 & 1.53 \\
\hline $\begin{array}{l}\text { Gauteng, South } \\
\text { Africa }^{6,9}\end{array}$ & 9.73 & 5.01 & 2.88 & 3.00 & 1.53 \\
\hline Argentina $^{6}$ & 11.30 & 1.46 & 3.32 & 10.19 & 3.13 \\
\hline $\begin{array}{l}\text { Republic of } \\
\text { Ireland }^{6,16}\end{array}$ & 4.87 & 0.49 & 0.86 & 4.56 & 1.10 \\
\hline Northern Ireland ${ }^{6,16}$ & 5.43 & 0.38 & 1.29 & 3.69 & 1.84 \\
\hline Wales $^{6,16}$ & 6.35 & 0.56 & 0.68 & 4.56 & 1.08 \\
\hline England $^{6,16}$ & 8.19 & 0.62 & 1.27 & 4.65 & 1.80 \\
\hline
\end{tabular}


can only be addressed by extending the surveys across many sites nationally.

The exclusion of ICUs from the survey may have a significant impact on the overall HCAl prevalence rate as critical care units contribute highly to HCAl prevalence, or often are the areas of a hospital with the highest prevalence of HCAls.

\section{Conclusion}

In conclusion, this was the first HCAI prevalence survey performed at $\mathrm{KHC}$, and demonstrated an HCAI prevalence rate of $7.67 \%$ with SSIs predominant at $4.60 \%$. This rate was comparable to studies done in other countries and shows a similar trend with predominance of SSI. This survey has provided a baseline against which future prevalence surveys can be compared. In the absence of targeted incidence surveillance, future repeat prevalence surveys can be an effective means of measuring the impact of interventions over time.

\section{Recommendations}

- Recognition and encouragement of operating theatre discipline should be emphasised regarding handwashing techniques, cleaning of surfaces and equipment, aseptic procedures, etc. to enhance behavioural change by all members who work in theatre.

- Sustained education of all clinical staff on the methods of prevention of HCAl.

- Implementing standard precautions, particularly best hand hygiene practices at the bedside.

- Patients scheduled for surgery need to be administered preoperative antibiotics 1-2 hours prior to incision, especially if surgery involves high risk of contamination (e.g. bowel surgery with rupture).

- Repeated pointprevalence surveys are needed to trace the changes in HCAl epidemiology in different years or seasons.

- Future surveys that are bigger, involving ICUs and inclusion of other facilities in the Northern Cape.

We hope that these findings will encourage the Northern Cape Department of Health and the KHC management to support further larger provincial wide, and repeated, surveillance and to facilitate strategies for the prevention and control of $\mathrm{HCAl}$ in $\mathrm{KHC}$ as well as the Northern Cape as a whole.

Disclosure statement - No conflict of interest was reported by the authors.

Acknowledgements - The authors thank Professor Adriano G Duse, Ms Lizette de Beer and Ms Antoinette Moolman from Wits University for the use of their technology, Sister Anacae Langeveld and Sister Myekie Radebe (Infection Control, Kimberley Hospital Complex) for assisting with data collection, and Ms Theanette Mulder, medical editor, School of Medicine, UFS, for the technical and editorial preparation of the manuscript.

\section{ORCID}

WJ Steinberg (ID http://orcid.org/0000-0001-9944-1807

JE Raubenheimer (D) http://orcid.org/0000-0003-3907-304X

\section{References}

1. Park K. Park's textbook of preventative and social medicine. 18th ed. Jabalpur, India: Banarsidas Bhanot Publisher; 2005.

2. Rothe $C$, Schlaich $C$, Thompson S. Healthcare-associated infections in sub-Saharan Africa. J Hosp Infect. 2013;85(4):257-67. https://doi.org/ 10.1016/j.jhin.2013.09.008

3. World Health Organization. Prevention of hospital-acquired infections. A practical guide. 2nd ed [Internet]. Geneva: World Health Organization. c2002 [cited 2017 Nov 13]. Available from: http:// www.who.int/csr/resources/publications/whocdscsreph200212.pdf

4. Kilgore ML, Ghosh K, Beavers CM, et al. The costs of nosocomial infections. Med Care. 2008;46(1):101-4. http://doi.org/10.1097/MLR. 0b013e3181468991

5. Bourn J. Report by the comptroller and auditor general. The management and control of hospital acquired infection in Acute NHS Trusts in England [Internet]. London: National Audit Office; 2000 [cited 2017 Oct 20]. Available from: https://www.nao.org.uk/wp-content/ uploads/2000/02/9900230.pdf

6. Durlach R, Mcllvenny G, Newcombe RG, et al. Prevalence survey of healthcare-associated infections in Argentina; comparison with England, Wales, Northern Ireland and South Africa. J Hosp Infect. 2012;80(3):217-23. https://doi.org/10.1016/j.jhin.2011.12.001

7. Lahsaeizadeh $\mathrm{S}$, Jafari $\mathrm{H}$, Askarian M. Healthcare-associated infection in Shiraz, Iran 2004-2005. J Hosp Infect. 2008;69(3):283-7. https://doi. org/10.1016/j.jhin.2008.05.006

8. Lowman W. Active surveillance of hospital-acquired infections in South Africa: implementation, impact and challenges. S Afr Med J. 2016;106(5):489. https://doi.org/10.7196/SAMJ.2016.v106i5.10783

9. Duse AG, Doherty L, Mcllvenny G, et al. Health-care associated infection (HCAl) prevalence survey: the South African pilot. Sixteenth Annual Scientific Meeting of the Society of Healthcare Epidemiology of America; Chicago, IL, USA, 2006.

10. Emori TG, Culver DH, Horan TC, et al. National nosocomial infections surveillance system (NNIS): description of surveillance methods. Am J Infect Control. 1991;19(1):19-35. http://doi.org/10.1016/0196-6553 (91)90157-8

11. Meers PD, Ayliffe GA, Emmerson AM, et al. Report on the national survey of infection in hospitals, 1980. J Hosp Infect. 1981;2(Suppl 1):1-53.

12. Emmerson AM, Enstone JE, Griffin $M$, et al. The second national prevalence survey of infection in hospitals-overview of the results. J Hosp Infect. 1996;32(3):175-90. http://doi.org/10.1016/ S0195-6701(96)90144-9

13. Health Protection Surveillance Centre. The third prevalence survey of healthcare associated infections in acute hospitals Republic of Ireland. Preliminary results 20th October 2006 [Internet]. c2006 [cited 2017 Oct 20]. Available from: https://www.hpsc.ie/az/micro biologyantimicrobialresistance/infectioncontrolandhai/surveillance/ hospitalpointprevalencesurveys/2006/results/File,2459,en.pdf

14. Gastmeier P, Kampf G, Wischnewski N, et al. Prevalence of nosocomial infections in representative German hospitals. J Hosp Infect. 1998;38(1):37-49. http://doi.org/10.1016/S0195-6701(98)90173-6

15. Kallel H, Bahoul M, Ksibi $H$, et al. Prevalence of hospital-acquired infection in a Tunisian hospital. J Hosp Infect. 2005;59(4):343-7. http://doi.org/10.1016/j.jhin.2004.09.015

16. Smyth ET, Mcllvenny G, Enstone JE, et al. Four country healthcare associated infection prevalence survey 2006: overview of the results. J Hosp Infect. 2008;69(3):230-48. http://doi.org/10.1016/j. jhin.2008.04.020

17. Magill SS, Edwards JR, Bamberg W, et al. Multistate point-prevalence survey of health care-associated infections. N Engl J Med. 2014;370 (13):1198-208. http://doi.org/10.1056/NEJMoa1306801

18. Marais E, Moodley A, Govender N, et al. Clusters of Klebsiella pneumoniae infection in neonatal intensive care units in Gauteng. S Afr Med J. 2006;96(9):813. 